\title{
Deslocamentos e adaptações - uma proposta de interpretação das narrativas de migrantes, unindo elementos da hermenêutica e da análise de discurso
}

\author{
Rejane Penna*
}

\begin{abstract}
Resumo: Buscou-se construir e testar metodologias de análise de entrevistas, discutindo as possibilidades de interpretação das narrativas de uma experiência específica: o deslocamento e a inserção na nova comunidade de indivíduos de diversas localidades urbanas para morar e trabalhar em Canoas, cidade industrial situada na região metropolitana do Rio Grande do Sul. As conclusões indicaram que os migrantes enfocados não se integraram efetivamente na vida da nova cidade, reconstruindo o novo espaço dentro de uma perspectiva enlaçada ao mundo anterior, onde a demarcação social não se fez entre casa e rua, mas entre centro e periferia.
\end{abstract}

Abstract: I will discuss the possibilities to interpret one specific experience: the displacement and insertion in a new community of individuals coming from several different urban localities to dwell and work in Canoas, an industrial city located in the metropolitan part of the state of Rio Grande do Sul. The findings indicate that the migrants focused here have not effectively integrated the life in the new city. In fact, they remade the new environment in the image old world that they had left, where a social line is drawn, not between home and street, but between centre and margin.

Palavras-chave: Migrações. Representações. Metodologia.

Key words: Migration. Representation. Methodology.

\section{Introdução}

O processo migratório nacional foi amplamente estudado por geógrafos, sociólogos, antropólogos e estatísticos, a partir de 1960. Entretanto, grande parte dos estudiosos que abordaram a questão tenderam a excluir os significados que os próprios migrantes atribuíam às suas experiências e vivências. Foram insuficientemente

Doutora em História Ibero-Americana. Professora do Centro Universitário La Salle (Canoas) e Historiógrafa do Arquivo Histórico do Rio Grande do Sul.

Estudos Ibero-Americanos. PUCRS, v. XXXII, n. 1, p. 99-115, junho 2006 
abordados os modos como se transferiram os usos e costumes dos lugares de origem ao de destino e a maneira pela qual tenderam a reinterpretar suas vidas na terra natal no contexto da cidade maior (Lucena, 1999).

Buscando auxiliar no preenchimento desta lacuna, o presente trabalho analisou a inserção de migrantes interurbanos na nova comunidade na ótica de seus sujeitos, utilizando a abordagem da história oral e história local. Primeiro, explicando como se compreende a articulação entre narrativa, memória e ideologia. Após, propondo uma metodologia de análise das narrativas, inserindo elementos da hermenêutica e da análise de discurso.

\section{História local, narrativa e memória no fenômeno migratório}

O recorte espacial delimitado para a presente análise foi a cidade de Canoas, a qual se estende por $131,1 \mathrm{~km}^{2}$ na região leste da Depressão Central do estado do Rio Grande do Sul. Atualmente, pela divisão mais freqüente, Canoas situa-se na macro-região nordeste, que concentra a industrialização e os maiores aglomerados urbanos, configurando-se como uma rede bem estruturada, possuindo grandes vantagens aglomerativas no eixo Porto AlegreCaxias do Sul e em algumas áreas adjacentes (Klarmann, 2002).

Alguns fatores aceleraram as modificações que levaram a localidade a evoluir de uma base agrícola, até as primeiras décadas do século XX, ao atual pólo industrial, como a expansão dos sistemas ferroviário e rodoviário modernos, iniciada pelo trecho Porto Alegre-São Leopoldo, facilitando as comunicações e os deslocamentos.

O fluxo para Canoas intensificou-se a partir de 1950, auxiliado também pela legislação regulamentadora dos loteamentos em Porto Alegre (Lei $\mathrm{n}^{\circ}$ 1.233), exigindo do loteador água, esgoto pluvial, pavimentação, rede elétrica, iluminação pública e dimensões controladas dos lotes, além de reservas para o verde público. Essa lei foi alterada, em parte, em 1966, e vigorou até 1979, por conseguinte, empurrando a população pobre para as periferias, auxiliando, junto com a instalação de indústrias, a constituição da chamada "Grande Porto Alegre" (Penna, Gayeski e Corbellini, 1997).

Mais tarde, buscando acompanhar o país no aprofundamento e na diversificação das atividades industriais, o Rio Grande do Sul pressionaria e obteria, em 1968, a instalação, no seu território, da Refinaria Alberto Pasqualini. O fato marcaria para sempre o perfil da cidade de Canoas, escolhida para sediar o grande complexo industrial, estimulando muitos outros investimentos estruturais, 
como a duplicação da BR-116 (Canoas - Perfil sócio-econômico, 1984).

Na perspectiva da região metropolitana de Porto Alegre, entre 1940 e 1950, Canoas teve a mais alta taxa de crescimento demográfico, com 7,83\% ao ano (Neves, Miranda, Gonçalves e Corbetta, 2003). Boa parte desse fomento não decorreu do simples crescimento vegetativo de sua população, mas de amplo e vigoroso movimento de migração interna, atraída pelas novas implantações industriais, pelo comércio e serviços necessários aos setores econômicos.

$\mathrm{Na}$ realidade, Canoas sofreu o mesmo processo ocorrido nas diversas regiões do país, ou seja, mudanças no formato das redes urbanas regionais, com peso crescente das aglomerações urbanas metropolitanas e dos centros urbanos médios.

Com esse suporte contextual, trabalhou-se a memória sobre a experiência migratória por intermédio de entrevistas, na perspectiva da história local, investigando-se, a partir das relações obrigatórias de trabalho, ou atividades não necessariamente ligadas às escolhas individuais, de que forma os indivíduos migrados vivenciaram e construíram as representações dessas experiências.

O foco centrado em uma cidade implicou na possibilidade de trabalhar uma situação complexa de forma densa, possibilitando a compreensão e generalização do processo a contextos mais amplos. Segundo Reznik (julho de 2005), a eleição de um local específico não implica uma simplificação do número de variantes e aspectos da trama social. O local alçado em categoria de análise pode vir a constituir uma nova densidade no quadro das interdependências entre agentes e fatores pertinentes a determinadas experiências históricas então eleitas pela lupa do historiador. Ao eleger o local como circunscrição de análise, como escala própria de observação, não se abandona as margens, os constrangimentos e as normas que, regra geral, ultrapassam o espaço local ou circunscrições reduzidas. Sendo assim, o exercício historiográfico incide na descrição dos mecanismos de apropriação - adaptação, resposta e criação - às normas que ultrapassam as comunidades locais (ibidem).

A partir do local consideramos que o espaço social é integrado pelos indivíduos que o percebem e o representam, a partir de suas formações ideológicas, remetendo a Paul Ricoeur (1969), que analisa toda ideologia como simplificadora e esquemática. Ela apresenta um caráter codificado para se dar uma visão de conjunto, não somente do grupo, mas da história e do mundo, formulando suas expressões preferencialmente com máximas, slogans e formas lapidares onde a retórica está sempre presente. Também tem uma 
função de conservação e de resistência às modificações, já que o novo coloca em perigo as bases que ela estabelece. A ideologia opera, assim, um estreitamento das possibilidades de interpretação dos acontecimentos, tendendo a permanecer estanque, enquanto a história se transforma. Então, todo o sistema de representações, independente do que enfoca, poderá ser associado a um escopo ideológico, pois a ideologia é operatória e não temática, sendo a partir dela que pensamos.

Os pressupostos sobre ideologia em Paul Ricoeur podem ser integrados ao de formação discursiva, conceito desenvolvido por Michel Foucault e utilizado pela segunda geração da Análise de Discurso Francesa (pós anos 70), que trabalha com a heterogeneidade discursiva (Pereira, 1991, p. 11). Considera-se essa composição menos problemática do que o proposto por Pêcheux, matriz teórica da vertente francesa da Análise de Discurso - unindo Foucault e Althusser.

Além dessa discussão, existem resistências por parte de muitos historiadores à utilização dos elementos da Análise de Discurso. Compreende-se as objeções, pois a Análise de Discurso constitui-se num projeto intelectual contraditório, uma vez que seu objeto, ora perspectiva-se lingüisticamente, ora ideologicamente (Pereira, 1991, p. 7).

Sabe-se que pela formação do historiador existem dificuldades a que ele consiga trabalhar com a língua, que se distingue da fala por ser o sistema de signos que exprime idéias, mas que obedece a suas próprias leis (Saussure, apud Dorneles, 1999, p. 151).

Entretanto, dentro da perspectiva de raciocínio desenvolvida por Pêcheux, a estrutura que organiza o sujeito como ser da linguagem e do inconsciente, estabelece uma interdependência entre as três regiões Real, Imaginário e Simbólico, onde um só tem existência pela presença dos outros dois (Dorneles, 1999, p. 154).

Nessa concepção de estrutura, o real está presente em três ordens: a do inconsciente, a da língua e a dos processos sócio-históricos. Entretanto, jamais teremos posse desse real, até pelo fato de que outro pesquisador poderá construir uma outra realidade acerca desse real, já que não acessível no seu todo, mas parte constitutiva da realidade. Aceita-se que os objetos se constituem em função do conhecimento humano, admitindo-se que a história não narra o real, mas uma realidade constituída pela/na trama da discursividade.

Acredita-se não ser possível separar língua e exterioridade, pois não há sentido no lingüístico sem a exterioridade. Então, um acontecimento histórico na visão de um indivíduo coloca em rela- 
ção sua memória, uma realidade estruturada e uma atualidade, resultando em determinada materialidade discursiva.

Instala-se, então, um espaço para o acontecimento, cujos objetos produzidos não estão presos a uma logicidade dada anteriormente, mas às condições históricas de produção de sentido. Essa historicidade impede o sentido de se sedimentar, porque há um real que insiste em ser considerado, sendo impossível de ser captado como um todo e do mesmo modo por todos os sujeitos do discurso.

Logo, esse encontro com o real poderá ser totalmente diverso do encontro que outros sujeitos do discurso tiveram, pois a língua, ao ser colocada em funcionamento pelos processos discursivos é afetada pelas condições sócio-históricas (Dorneles, 1999, p. 160). E é no ponto onde se dá a injunção de língua, sujeito e história que se constitui o lugar da opacidade da língua, do equívoco - esse é o espaço onde trabalha a interpretação.

Configura-se, então, o conceito que utilizar-se-á da Análise de Discurso, ou seja, o de formação discursiva como aquilo que numa formação ideológica dada, a partir de uma posição numa conjuntura específica delimita o que pode e o que deve ser dito. Ou seja, as formações ideológicas concretizam-se nas formações discursivas.

A ideologia fornece as evidências pelas quais todo mundo sabe o que é um estudante, um ladrão, a violência, o papel da religião, etc., evidências que mascaram assim, sob a transparência da linguagem, o que foi denominado de caráter material do sentido das palavras e dos enunciados (Pêcheux, apud Pereira, 1991, p. 14).

Esses pressupostos indicam que as palavras e expressões mudam de sentido de acordo com as posições sustentadas por aqueles que as empregam, adquirindo seu significado em referência às formações ideológicas nas quais essas posições se inscrevem. Enfatiza-se a ilusão do sujeito em ser a fonte do sentido e do seu pensamento e, ao descentralizar essa noção de sujeito, centraliza-se a problemática nos sistemas de representação.

Por fim, outro elemento a ser levado em consideração em qualquer narrativa é a memória dos indivíduos. As preocupações e análises sobre memória sempre se fizeram presentes no campo social e das Ciências Humanas, envolvendo noções de temporalidades, lembranças, oralidades, subjetividades, factualidades e espacialidades. Suas técnicas e seus instrumentos analíticos e metodológicos é que não foram problematizados como estão sendo contemporaneamente focando sociedades complexas em geral e a experiência de vida de grupos em espaço de mudanças socioculturais (Tedesco, 2004, p. 27). 
Articulada ao contexto espaço-temporal, às representações e ideologias, a memória atua não como consciência basilar do passado, mas esforça-se para reabrir o tempo a partir da implicação do presente, possibilitando a utilização de mecanismos para enfrentar outras experiências (Merleau-Ponty, 1987, apud Penna, 2005).

Dentro deste quadro integrado pelos elementos contextuais - a cidade a partir de sua decolagem industrial e o processo migratório interno; pelo quadro conceitual que reúne memória, história local, ideologia e formação discursiva no sistema oral narrativo, acredita-se poder compreender a dinâmica migracional para além das estatísticas. Busca-se o que Roland Barthes (1996) denominou de estrutura que liga relatos pessoais do vivido e rememorado a uma interpretação consistente, capaz de compreender, desvendar e enunciar nos moldes exigidos pela ciência.

\section{A interpretação das narrativas}

Ao pensar-se nas subjetividades e nessa relação com o outro, Paul Ricoeur tem se apresentado, na tradição contemporânea, como um expoente nessa preocupação de se compreender o dito distanciando-se em parte da pretensão psicanalítica e concentrando-se na linguagem:

Nessa direção, o narrador expressa em sua fala seu contexto ideal, pois traz de volta coisas perdidas no tempo. Ele as significa e as coloca em movimento como um mecanismo de compor pedaços de uma história que, ao ser vivida, demonstra a possibilidade de trazer dados que se conectam com o imaginário da época. Ao que tudo indica, o narrador diz de um mundo que ele construiu com cacos que restaram do passado. Este mundo representa para o ouvinte histórias que têm seu valor, de forma individual ou coletiva. Isso porque o "mundo contado, é o mundo do personagem e é contado pelo narrador" (Ricoeur, 1995, p. 147).

Mas poucos pesquisadores na área das Ciências Humanas satisfazem-se apenas com o "mundo contado", buscando relacionar as subjetividades presentes nos relatos orais com as fontes escritas e demais vestígios, tentando reconstruir a trama histórica. Pensa-se que a experiência de um sujeito preciso não escapa das concretudes socioculturais que configuram seu lugar no mundo. Mesmo quando o registro muda para os relatos orais, não se pode ignorar a existência de indícios materializados em documentos escritos, fotos, objetos, ícones, etc., a que Kofes (2001, p. 21) denomina inscrições objetivas. 
Isso torna complexo compreender a correspondência entre uma vida como é vivida (o que atualmente acontece); uma vida como experiência (imagens, sentimentos, emoções, pensamentos e significações conhecidas pelas pessoas que as vivenciaram) e uma vida como contada (narrativa, influenciada pelas convenções culturais do contar, pela audiência e pelo contexto) (ibidem, p. 48).

Trabalhando um método interpretativo das narrativas dentro dos pressupostos apontados, levou-se em consideração que os discursos não se revelam de imediato, necessitando de uma metodologia de análise que desvende os nexos e as relações estabelecidos entre experiência, memória e narrativa. Nesse sentido, operacionalizou-se a tarefa de interpretar as narrativas, estudando os modelos de análises qualitativas já existentes.

Com elementos integrantes de qualquer análise qualitativa, nas suas características de hermenêutica controlada, baseada na dedução - a inferência ${ }^{1}$ - buscou-se recursos para compreender a entrevista para além de simples intuições ou impressões precipitadas (Szymanski, Almeida e Prandini, 2002, p. 63). Tentou-se na prática a superação da ilusão de transparência (Bardin, 1995, p. 9).

Como o discurso é caracterizado pela dispersão, por uma desordem aparente de sentidos, foi necessário buscar o desvelamento do conteúdo ou o nexo discursivo pela formação de determinações discursivas, possibilitando, assim, a passagem da desordem para a regularidade. Esse processo foi proporcionado pela análise das formações discursivas, componentes das formações ideológicas dadas, pois as palavras variam seu sentido ao passarem de uma formação discursiva para outra, mudando sua relação com a formação ideológica (Haroche et al., 1975, apud Orlandi, 1988, p. 18).

Da hermenêutica, adotou-se a problemática de saber como é possível interpretar as descrições de sentido subjetivamente intencionais, tendo em conta o fato de passarem pela subjetividade do próprio intérprete (ibidem, p. 65). Tomou-se como ponto de partida a metodologia descrita e aplicada por pesquisadoras na área da Educação, no caso o trabalho desenvolvido por Szymanski, Almeida e Prandini (2002).

Iniciou-se apreendendo o sentido do todo, como base para delinear as unidades de significado, como um procedimento que viabilizou o tratamento dos dados. Ressalte-se que essas unidades não estavam prontas no texto, mas existiam na perspectiva do pesquisador. Ou seja, colocou-se em evidência os significados em função do fenômeno que se estava investigando - no caso, as repre-

1 Para situar o conceito de inferência em análises qualitativas, ver Constantino (2002). 
sentações sobre a experiência migratória. A síntese realizada concretizou a imersão do pesquisador nos dados e sua forma particular de agrupá-los segundo a sua compreensão, pois essa construção, conforme se afirmou, dependeu da experiência pessoal do pesquisador-intérprete, das teorias do seu conhecimento, suas crenças e valores. A carga de subjetividade contida não foi problema, já que revestida pela formação do pesquisador e pela explicitação metodológica.

De acordo com as autoras que inspiraram a aplicação de parte deste modelo hermenêutico, chama-se este momento de explicitação de significados e a síntese expressa em proposições irá indicar o sentido do todo (Szymanski, Almeida e Prandini, 2002, p. 66). Objetivou-se não apenas descrever, mas desvelar o sentido do texto, numa análise que implicou em entender como o fenômeno se inseriu no contexto do qual fez parte.

Aplicando a metodologia, no Quadro 2 escolheu-se trechos da entrevista que enunciavam a visão de mundo do depoente, integrante de uma determinada formação discursiva, buscando, ao final do quadro, seu significado sintetizado.

Após, recortou-se trechos do relato da inserção do depoente na cidade, com uma primeira descrição, no Quadro 3, denominada de Descrição I. Então, iniciou-se a reflexão, realizando-se o trabalho intradescritivo, a partir de leituras e releituras do texto de referência. No Quadro 4, reescreveu-se a Descrição I, no sentido interpretativo, a partir da seleção dos itens emergentes, referidos como unidades de significados, denominando-se de Descrição II, onde surgiu o oculto por intermédio do aparente.

Unindo esses elementos, criou-se uma metodologia articulando a hermenêutica com a Análise de Discurso, permitindo ordenar a dispersão dos enunciados e desvelar os sentidos das narrativas.

Passando à aplicabilidade da metodologia, a partir dos aportes acima, selecionou-se pessoas entrevistadas a partir de uma perspectiva propositadamente diversificada, a fim de verificar o leque de representações dentro de uma experiência em comum: a migração para Canoas. Além disso, compartilhavam o fato de serem oriundas de outros meios urbanos do Rio Grande do Sul, encontrarem-se, no mínimo, há 10 anos na cidade (tempo suficiente para experienciar e narrar o processo com alguma perspectiva) e de desenvolverem atividades produtivas.

Observa-se algumas imprecisões quanto a determinadas informações sobre os depoentes, devido ao fato das entrevistas, realizadas entre 1999 e 2000, serem oriundas de outro projeto (Canoas 
- para lembrar quem somos), com objetivos diferenciados deste, mas com abordagem focada na cidade de Canoas. 


\begin{tabular}{|c|c|c|c|}
\hline $\begin{array}{c}\text { Quadro 1 } \\
\text { Dados } \\
\text { depoente }\end{array}$ & $\begin{array}{c}\text { Quadro } 2 \\
\text { Formação Discursiva }\end{array}$ & $\begin{array}{c}\text { Quadro } 3 \\
\text { Relatos/Depoimentos - } \\
\text { Descrição I }\end{array}$ & $\begin{array}{c}\text { Quadro } 4 \\
\text { Unidades } \\
\text { de Signifi- } \\
\text { cado - } \\
\text { Descrição } \\
\text { II }\end{array}$ \\
\hline $\begin{array}{l}\text { Idara } \\
\text { Rocha, } \\
\text { nascida } \\
\text { em 1944 } \\
\text { em São } \\
\text { Sepé. } \\
\text { Professo- } \\
\text { ra, dona } \\
\text { de uma } \\
\text { pequena } \\
\text { escola } \\
\text { particu- } \\
\text { lar. Mora } \\
\text { no Bairro } \\
\text { Niterói. } \\
\text { Mudou- } \\
\text { se para } \\
\text { Porto } \\
\text { Alegre e } \\
\text { depois } \\
\text { para } \\
\text { Canoas } \\
\text { adoles- } \\
\text { cente. }\end{array}$ & $\begin{array}{l}\text { "Continuo na educação } \\
\text { porque continuo acredi- } \\
\text { tando na educação. Falar } \\
\text { em crise acho que não } \\
\text { justifica, porque quando a } \\
\text { gente quer uma coisa e } \\
\text { luta por ela, a crise nos dá } \\
\text { ais força e mais ânimo".; } \\
\text { "Parece que com a crise } \\
\text { dos valores estão se ques- } \\
\text { tionando onde está o } \\
\text { respeito para o professor, } \\
\text { para o aluno. Então é só } \\
\text { retomar os valores, traba- } \\
\text { lhar de forma participati- } \\
\text { va e respeitosa, onde } \\
\text { todos se realização bem } \\
\text { mais fácil. Preparo consci- } \\
\text { ente do aluno. Ele tem } \\
\text { que saber o que neste } \\
\text { momento estamos viven- } \\
\text { do.” } \\
\text { "Quando nós saíamos em } \\
\text { 40, num grupo, era um } \\
\text { grupo feliz, porque tinha } \\
\text { assistência religiosa, todos } \\
\text { estudavam, tiveram bons } \\
\text { relacionamentos e alguns } \\
\text { até contraíram casamento } \\
\text { e estão dando prova de } \\
\text { valor e da importância da } \\
\text { família bem constituída. } \\
\text { Hoje o que estamos ven- } \\
\text { do? A problemática da } \\
\text { família. Acho que quando } \\
\text { na família a estrutura não } \\
\text { é uma estrutura firma, } \\
\text { todas as outras estruturas } \\
\text { se abalam”““ } \\
\text { Síntese: Crise de valores. } \\
\text { Solução: educação e refor- } \\
\text { ço dos valores familiares }\end{array}$ & $\begin{array}{c}\text { “Se aqui foi fácil ou difí- } \\
\text { cil? Depende de cada um. } \\
\text { Eu me envolvi tanto aqui } \\
\text { no bairro que não deu } \\
\text { para sentir. Quando a } \\
\text { gente notou viu que iam } \\
\text { acontecendo coisas, coisas } \\
\text { boas". } \\
\text { "Gostaria de falar de um } \\
\text { trabalho que eu assumi na } \\
\text { Paróquia São Paulo há } \\
\text { nove anos. Fomos procu- } \\
\text { rados pelo Padre Werno } \\
\text { para que assumíssemos } \\
\text { participar das missas [...]. } \\
\text { Trouxe a proposta para a } \\
\text { escola e aceitamos. Os } \\
\text { professores aceitaram, } \\
\text { pois era a oportunidade } \\
\text { da criança com a família } \\
\text { participar da comunida- } \\
\text { de. } \\
\text { "Olhando o quadro do } \\
\text { nosso bairro, como era } \\
\text { mais antigamente, tão } \\
\text { desamparado, pouco } \\
\text { assistido e hoje, com as } \\
\text { ruas todas arrumadinhas, } \\
\text { todo bem iluminado, isto } \\
\text { é muito importante. Uma } \\
\text { vez tínhamos estes pro- } \\
\text { blemas que foram resol- } \\
\text { vidos, só que hoje des- } \\
\text { cambou a marginalidade } \\
\text { com uma agressividade } \\
\text { muito grande, especial- } \\
\text { mente quanto a assaltos. } \\
\text { [...] ma vez havia um tipo } \\
\text { de problema que hoje foi } \\
\text { resolvido: o barro na rua, } \\
\text { falta de água, falta de luz. } \\
\text { Mas tinha mais tranquili- } \\
\text { dade e uma certa paz. } \\
\text { Hoje temos tudo mas não } \\
\text { temos tranquilidade”. }\end{array}$ & $\begin{array}{c}\text { Luta pes- } \\
\text { soal, Famí- } \\
\text { lia e Co- } \\
\text { munidade } \\
\text { Atualida- } \\
\text { de: confor- } \\
\text { toe insegu- } \\
\text { rança } \\
\text { Passado: } \\
\text { precarie- } \\
\text { dade mate- } \\
\text { rial, mas } \\
\text { paz } \\
\text { Moderni- } \\
\text { zação- } \\
\text { problemas } \\
\text { Síntese: } \\
\text { venceu-se } \\
\text { pelo esfor- } \\
\text { ço pessoal, } \\
\text { alicerçado } \\
\text { pela edu- } \\
\text { cação e } \\
\text { Família. } \\
\text { Hoje tenta- } \\
\text { se congre- } \\
\text { gar a co- } \\
\text { munidade } \\
\text { por inter- } \\
\text { médio } \\
\text { destes } \\
\text { laços, mas } \\
\text { a moderni- } \\
\text { zação pode } \\
\text { colocar } \\
\text { tudo em } \\
\text { risco. }\end{array}$ \\
\hline
\end{tabular}


Dados depoente Clodomiro Koch

Nasceu

em São

Sebastião

do Caí no

ano de

1929. Aos

três anos

mudou-

se para

Monte-

negro e

depois

Porto

Alegre. O

pai traba-

lhava

com

transpor-

te fluvial

de cargas.

Clodomi-

ro insta-

lou-se em

Canoas

nos anos

cinquen-

ta, após o

casamen-

to. Traba-

lhou

como

marce-

neiro e,

depois,

mecânico

de aero-

naves e

de auto-

móveis.

Morador

do Bairro

Igara
"Hoje cada um é dono do seu nariz. Enquanto estavam sob os meus poderes minha norma era uma: só saíam de cada juntoconosco. Saíam para o colégio, mas para sair junto com os colegas no colégio a gente não deixava, só se nós estivesse junto. Sempre foram criados dentro do pátio. [...] . Hoje estão casados e sempre tem diferença na forma de criação dos filhos. Tem certas coisas que eu até não gosto. O sistema que estão usando é muito liberal, não é uma coisa justa. Eu gosto das coisas justas, com limites e certo, esse negócio de muita liberdade, os filhos fazerem o que bem entendem, deixar correr, não me cabe".

"Deus é um só, religião tem um monte, mas não seguem o que deve ser seguido. E outra, esse negócio de ser crente, evangélico tudo bem, mas esses pastores, as interpretações deles sobre a bíblia, aquilo não vem fechar com as palavras que estão escritas. Eles interpretam uma coisa e é outra. Depois começam a ensinar o que não é. Eu digo para ela - religião não é para discutir, mas quem me disser isso eu sou obrigado a discutir. Ela me disse que os pastores interpretaram que Jesus Cristo não foi crucificado. Ele foi atado num pau. Aí eu disse -é mentira quem disse isso!. Porque desde que eu e conheco por

\section{Relatos/Depoimentos} Descrição I

"Depois que casei é que vim para Canoas. Eu pagava aluguel em Porto Alegre e era um lugar muito ruim, apertado".

"O bairro era mancíssimo.

Podia dormir no meio do campo tranquilo. Hoje não é liberal de ir ali no boteco, de dia descansado. Pode ser assaltado no meio da rua. Aqui acontece seguido, na padaria, na fruteira. Aparece no jornal, a polícia correndo atrás dos marginais. Mas isso foi depois da criação da Vila Guajuviras e no fundo da Mathias. Dali eles vieram".

Unidades

de Significado

Descrição II

Canoas melhoria de vida Passado tranquilo.

Presente inseguro devido ao crescimento

Síntese: crise de valores. Sistema familiar atual é muito liberal. Interpretações religiosas são errôneas. 
Clair

Beltrame,

nasceu

em Getu-

lio Var-

gas, em

1937.

Veio para

Canoas

em 1958,

após

morar em

Nova

Prata.

Possui

uma

oficina

de cha-

peação.

Também

participa

da ativi-

dade

religiosa-

benefi-

cente

Cruz de

Amor.

Morador

do Bairro

Igara. gente e leio na sagrada escritura - Jesus foi crucificado. São Sebastião foi amarrado num toco e flechado. Isso eu leio na bíblia. Tem muitas palavras que deixam a gente meio torto de se ler. “

"O sentimento religioso vem principalmente da mãe e da família da mãe que tinha padre. Da família do meu pai eram em 12 irmãos e da minha mãe também eram 12 . No almoço, de noite, sempre se rezava. Agora a minha mãe, quando moramos em tempo em Sananduva, na época, quando terminou a guerra, em 1942-45, nós rezávamos o terço todas as noites. Isso era infalível. Nós éramos pobres, mas dos 6 filhos, ninguém ia dormir sem rezar o terço".

Síntese: Valores transmitidos pela Religião e família
Relatos/Depoimentos Descrição I

"Canoas se delineava como uma cidade do futuro, por causa da BR116. Se falava muito sobre a Br. Então eu vim e me instalei e estou por quarenta anos aqui.". "A nossa rua era a Curupi. Era a única que não era asfaltada. Aqui se chamava desmembramento da Vila Igara, por isso ficou muitos anos sem calçamento. Quando cheguei aqui não tinha padaria, supermercado. "

"Eu pessoalmente acho que o bairro não devia crescer muito, principalmente não deixar construir edifícios altos. Isso é um problema. [...] Nosso bairro parece mais uma cidadezinha do interior. Isso é que me atrai".

"Apesar de já ter alguns assaltos é um bairro de muitas etnias, de muita gente do interior como Garibaldi: tutti buona gente! [...] Têm muitos brasileiros. Hoje nós convivemos bem com todos. Nós italianos temos uma festa que se faz uma vez por anos-é o jantar dos italianos.
Unidades de Significado

Descrição II

Canoas esperança

Precariedade local ao chegarem.

Bairro ao crescer distanciase do local de origem

Somos italianos e convivemos com os brasileiros. 


\begin{tabular}{|c|c|c|c|}
\hline $\begin{array}{c}\text { Lucy } \\
\text { Lopes d } \\
\text { Oliveir } \\
\text { nasceu } \\
\text { em Bag } \\
\text { e está h } \\
\text { doze } \\
\text { anos en } \\
\text { Canoas } \\
\text { tendo } \\
\text { sido } \\
\text { criada e } \\
\text { Cachoe } \\
\text { ra do } \\
\text { Sul.(nã } \\
\text { foi prec } \\
\text { sada a } \\
\text { data do } \\
\text { nasci- } \\
\text { mento) } \\
\text { Foi aux } \\
\text { liar de } \\
\text { escritórì } \\
\text { e estudo } \\
\text { Estudo } \\
\text { Sociais } \\
\text { Coorder } \\
\text { a Crech } \\
\text { da Hort } \\
\text { Comun } \\
\text { tária e } \\
\text { Presidel } \\
\text { te da } \\
\text { Cooper } \\
\text { tiva de } \\
\text { Prestaçã } \\
\text { de Serv } \\
\text { ços da } \\
\text { vila Unn } \\
\text { ão dos } \\
\text { Operá- }\end{array}$ & $\begin{array}{l}\text { “Tem muita gente aco- } \\
\text { modada e a televisão } \\
\text { também nos atrapalha } \\
\text { muito, é nossa grande } \\
\text { inimiga, altamente con- } \\
\text { sumidora, leva tudo que é } \\
\text { coisa para dentro de casa. } \\
\text { As pessoas ficam presas } \\
\text { na TV.” } \\
\text { "Hoje vemos que quem } \\
\text { está na luta mesmo são os } \\
\text { guerreiros que têm fé, } \\
\text { quem está aí é quem } \\
\text { batalha mesmo. Apreendi } \\
\text { em cursos que não adian- } \\
\text { te igreja cheia, se por trás } \\
\text { estão buscando outra } \\
\text { coisa senão o Cristo. Qua- } \\
\text { lidade não é quantidade.". } \\
\text { Síntese: Crise de valores: } \\
\text { TV impinge valores } \\
\text { destrutivos. } \\
\text { Religiosidade só é válida } \\
\text { com } \\
\text { Verdadeira crença. }\end{array}$ & $\begin{array}{l}\text { "Morei um tempo em } \\
\text { Cachoeira. Depois com o } \\
\text { desemprego a gente veio } \\
\text { para Canoas, em busca de } \\
\text { uma melhor situação } \\
\text { financeira". } \\
\text { "Foi em } 1987 \text { que iniciou } \\
\text { minha participação no } \\
\text { Clube de Mães, mas não } \\
\text { fui fazer trabalho com as } \\
\text { outras mães. A mim } \\
\text { coube o trabalho com as } \\
\text { crianças de anunciar o } \\
\text { evangelho, cantinhos e } \\
\text { orações". } \\
\text { "As irmãs e os freis aju- } \\
\text { dam os que estão preci- } \\
\text { sando. Eles saem e e vão } \\
\text { para outros lugares onde } \\
\text { precisam mais deles. Aqui } \\
\text { a gente já se organizou, } \\
\text { temos água, luz, os gru- } \\
\text { pos organizados. Se pro- } \\
\text { cura saídas alternativas } \\
\text { para emprego. A creche é } \\
\text { um exemplo". }\end{array}$ & $\begin{array}{c}\text { Canoas- } \\
\text { esperança } \\
\text { Integração } \\
\text { na comu- } \\
\text { nidade por } \\
\text { Intermédio } \\
\text { do ensino } \\
\text { de valores } \\
\text { às crianças } \\
\text { Sob a } \\
\text { inspiração } \\
\text { de religio- } \\
\text { sos, nos } \\
\text { organiza- } \\
\text { mos e } \\
\text { buscamos } \\
\text { soluções. }\end{array}$ \\
\hline
\end{tabular}

Esta pequena amostra proporciona mais questionamentos do que respostas, e está longe de esgotar as possibilidades de interpretação das entrevistas, mas permite que iniciemos uma reflexão. No Quadro 1, Dados do depoente, observamos de onde falam os sujeitos do discurso, bem como os elementos que têm em comum, 
como, por exemplo, o longo tempo de moradia na cidade e a origem humilde: são descendentes de pessoas com baixo poder aquisitivo, exercendo atividades que não exigem investimentos significativos em termos de educação formal (ainda que Lucy possua formação melhor qualificada). Também todos são oriundos de pequenas localidades do interior gaúcho, que, na nova cidade, não agregaram um novo perfil na sua inserção social, inclusive habitando localidades periféricas. Canoas pareceu-lhes, já que passavam por dificuldades financeiras e este não era seu primeiro deslocamento, como plena de potencialidades para a melhoria financeira de suas vidas.

O Quadro 2, Formação discursiva, revela as ideologias presentes nas formações discursivas, que remetem a valores alicerçados em elementos como religião e/ou educação, respaldados pelo núcleo fundamental - a família. A preocupação com uma suposta crise de valores está presente no discurso dos depoentes, representada justamente pelo risco da destruição desse sistema legado pela família. O elemento religioso demonstrou ser uma forma de manter o elo com o passado, à medida que a lembrança da religiosidade remeteu à união familiar.

No Quadro 3 - Relatos/Depoimentos - Descrição I, as narrativas referem-se ao processo de integração na nova cidade, indicando obstáculos representados por precariedades infraestruturais, à medida que, com recursos deficientes, os migrantes foram obrigados a habitar zonas pouco valorizadas. Em seus depoimentos destacaram sua participação na resolução das deficiências infra-estruturais como uma forma de construir, moldar o novo espaço, demonstrar que não estava efetivamente pronto, necessitando da interferência daquele que chegava para configurar-se como plenamente habitável.

Uma forma de integração foi proporcionada pelas atividades junto a associações comunitárias ou religiosas. Também a etnicidade, presente na valorização da origem italiana, na fala de Clair Beltrame, foi elemento presente para proporcionar a afirmação de uma identidade no novo espaço.

Por outro lado, mesmo que fator inicial de atratividade para os migrantes, o crescimento de Canoas foi visto com algum temor, fazendo a cidade distanciar-se ainda mais dos seus locais de origem.

Dentre as dificuldades enfrentadas ao chegarem, não mencionaram algum tipo de discriminação pelos moradores já estabelecidos. É provável que, devido à proximidade cultural, bem como aos locais onde se instalaram - plenos de outros migrantes - não 
tenham sofrido grandes rupturas no seu cotidiano, pois o deslocamento de um grupo de uma região a outra não significa a perda do seu conhecimento adquirido, mas sim a justaposição de significados e valores culturais.

Transportando as narrativas, dentro dos percursos metodológicos construídos, chegou-se ao Quadro 4 - Unidades de significado, podendo-se então ler que nas narrativas estavam presentes representações que contrapunham as conquistas infra-estruturais atuais a uma modernização problemática, permeada pelos fatores da insegurança e violência. Os migrantes então representaram que venceram na nova cidade pelo esforço pessoal, proporcionado pela formação religiosa e familiar, os quais tentariam ainda hoje passar para a comunidade, por intermédio de suas participações em associações religiosas e comunitárias.

\section{Encaminhando conclusões}

O relato oral produziu um corpo documental cuja natureza convida o pesquisador a exercitar sua sensibilidade para poder ler nas marcas pessoais, que aparentemente individualizam o depoente, um texto que narra a experiência coletiva daquele grupo de migrantes.

As representações dos migrantes puderam ser melhor compreendidas ao serem inseridas em um sistema ideológico expresso dentro de determinadas formações discursivas. Nelas evidenciaram-se os temores que a modernização de um centro urbano de porte médio como Canoas poderia ocasionar em um modo de vida ancorado pelos valores transmitidos pela família e pela religião.

Inserindo trechos enfocando a inserção na nova cidade, verificou-se que por intermédio da participação em organizações como igreja, horta comunitária ou atividades que exigiam o contato com o público, os migrantes foram elaborando o que, em uma primeira análise, assemelhava-se a um sentimento de pertencimento ao local de moradia e à cidade, um desejo de auto-organização e busca de transformação da realidade local. Mas um olhar direcionado metodologicamente encaminhou o que dificilmente outro tipo de fonte que não a oral demonstraria, ou seja, um painel de uma inserção contraditória de pessoas que supostamente integraram-se plenamente em uma cidade na região metropolitana de Porto Alegre.

A leitura revelou que uma cidade industrial de porte médio como Canoas impõe um novo ritmo de trabalho e embora alguns 
migrantes continuassem exercendo tarefas semelhantes às que desenvolviam, ingressaram em uma nova dinâmica - a do tempo industrial.

A cidade sugere a racionalização do orçamento, propõe uma vida individualizada, com experiências e percepção de ritmos diferentes do que possuíam nas pequenas cidades. Este movimento não foi percebido nos relatos estudados, sendo que os migrantes lutaram para manter os hábitos e as tradições de seus locais de origem. E isso foi possível porque a tradição possui sempre uma dimensão cultural que é transmitida de geração a geração enquanto lhe for atribuído valor.

Sabe-se que tanto a sociedade quanto seus indivíduos são dotados da capacidade de esquecer e de reinventar significados; enfrentando com os meios mais adequados os novos problemas que em geral se apresentam. No caso dos migrantes, ao invés de recorrer a novas formas de pensar suas vivências para enfrentar o desafio de um meio urbano estranho, recorreram aos elementos presentes em sua cultura de origem, aos quais cada vez mais se apegaram, compreendendo os novos tempos e a quebra de tradições como uma ameaçadora crise de valores que poderia tragar um modo de vida.

Seguindo um raciocínio semelhante ao de Lucena (1999), para o morador do bairro comunitário, a demarcação social não se fez entre casa e rua, mas entre centro e periferia. Os códigos da casa e da rua são baseados na família, amizade, lealdade, vizinhança e compadrio. O código do centro da cidade é baseado em leis universais, no anonimato, no perigo e na vida pública. Dessa forma os migrantes afirmaram residir em Canoas, mas preferiram refugiarse no bairro comunitário, passando meses ou anos sem freqüentar o centro urbano, ignorando, inclusive, as transformações que sofria a cidade, caso não afetassem o nicho que construíram para si.

Na realidade, não se integraram efetivamente na vida da nova cidade, mas fixaram-se em localidades em muitos aspectos semelhantes de onde partiram, procurando reconstruir o novo espaço dentro de uma perspectiva enlaçada ao mundo anterior. 


\section{Referências}

BARDIN, L. Análise de conteúdo. Lisboa: Edições 70, 1995.

BARTHES, Roland. Aula. São Paulo: Cultrix, 1996.

Canoas - Perfil sócio-econômico. Câmara de Indústria, Comércio e Serviços de Canoas, 1996; Canoas. Coleção de Monografias Municipais. Nova Série, n. 66. Rio de Janeiro: IBGE, 1984.

CONSTANTINO, Núncia Santoro de. Pesquisa histórica e análise de conteúdo: pertinência e possibilidades. Estudos Ibero-Americanos, Porto Alegre, PUCRS, v. 28, n. 1, p. 167-182, 2002.

DORNELES, Elizabeth Fontoura. O discurso do MST: um acontecimento na estrutura agrária brasileira. In: INDURSKY, Freda; FERREIRA, M. Cristina (Orgs.). Os múltiplos territórios da análise de discurso. Porto Alegre. SagraLuzzato, 1999.

FERREIRA, Lucia; ORRICO, Evelyn (Orgs.) Linguagem, identidade e memória social. Rio de Janeiro: DP\&A, 2002.

GUIMARÃES, Gleny Terezinha Duro. Historiografia da cotidianidade - nos labirintos do discurso. Porto Alegre: Edipucrs, 2000.

INDURSKY, Freda; FERREIRA, M. Cristina (Orgs.). Os múltiplos territórios da análise de discurso. Porto Alegre. Sagra Luzzato, 1999.

KLARMANN, Herbert. Regionalização e planejamento: reflexões metodológicas e gerenciais sobre a experiência gaúcha. Ensaios FEE, Porto Alegre, v. 23, número especial, 2002.

KOFES, Suely. Itinerário, em busca de uma trajetória. Campinas: Mercado de Letras, 2001.

LUCENA, Célia. Artes de lembrar e de inventar: (re)lembranças de migrantes. São Paulo: Arte \& Ciência, 1999.

NEVES, Gervásio; MIRANDA, Luiz Gonçalves; CORBETTA, Elizabeth (Orgs.). Atlas Social da Região Metropolitana de Porto Alegre. Porto Alegre: Metroplan, 2003.

ORLANDI, Eni. Discurso e leitura. São Paulo/Campinas: Cortez/Unicamp, 1988.

PENNA, Rejane. Fontes orais e historiografia - avanços e perspectivas. Porto Alegre: Edipucrs, 2005.

_ ; GAYESKI, Miguel; CORBELLINI, Darnis. Estância Velha. Canoas - para lembrar quem somos. Canoas: Canoas Tecnocópias, 1997.

PEREIRA, Aracy Ersnt. Uma introdução à análise do discurso. Letras de hoje. Revista do Curso de Pós-Graduação em Lingüística e Letras, Centro de Estudos da Língua Portuguesa, PUCRS, 1991.

REZNIK, Luiz. Apresentação na coordenação Simpósio História Local, XXIII Encontro Nacional de História, julho/2005, ANPUH. 
RICOEUR, Paul. Le conflit des interprétations. Essais d'herméneutique. Paris: Seuil, 1969.

. Tempo e narrativa. São Paulo: Papirus, 1995. t. 2.

SZYMANSKI, Heloisa. Perspectiva para análise de entrevistas. In: SZYMANSKI, Heloisa (Org.). A entrevista na pesquisa em educação: a prática reflexiva. Brasília: Plano Editora, 2002.

TEDESCO, João Carlos. Nas cercanias da memória: temporalidade, experiência e narração. Passo Fundo/Caxias do Sul: UPF/EDUCS, 2004. 